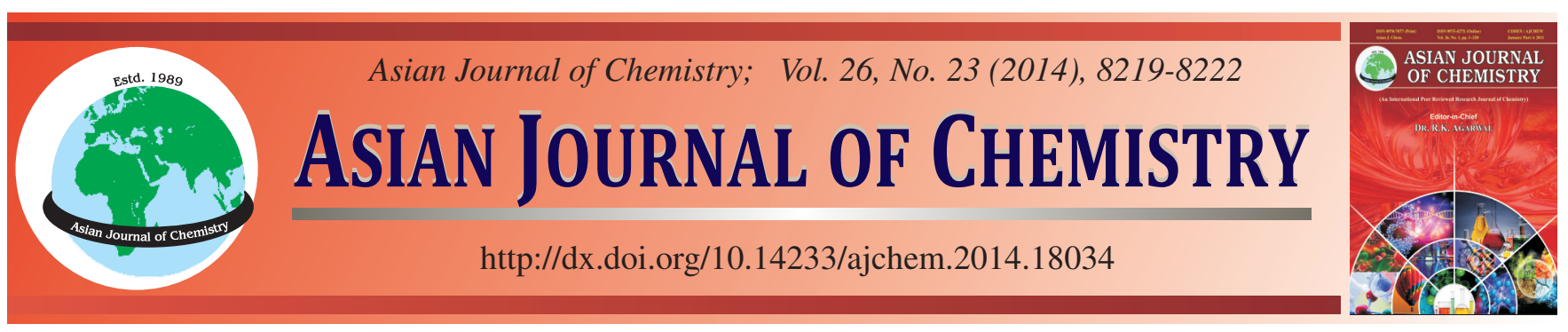

\title{
Total Synthesis of Apigenin Glycosides and the Effect of These Compounds on Polyphenol Oxidase Enzyme Activity
}

\author{
S. Beyaztas ${ }^{1, *}$, M. Kucukislamoglu ${ }^{2}$, F. Sonmez ${ }^{2}$, M. Nebioglu ${ }^{2}$, S. Besoluk $^{3}$, M. Arslan ${ }^{2}$, M. Zengin ${ }^{2}$ and O. Arslan $^{1}$
}

${ }^{1}$ Balikesir University, Science and Art Faculty, Department of Chemistry/Biochemistry Section, Balikesir, Turkey ${ }^{2}$ Sakarya University, Science and Art Faculty, Department of Chemistry/Organic Chemistry Section, Sakarya, Turkey

${ }^{3}$ Sakarya University, Faculty of Education, Department of Science Education, Sakarya 54300, Turkey

*Corresponding author: Fax: +90 266 6121215; Tel: +90 266 6121278; E-mail: beyaztas@ balikesir.edu.tr

We have succeeded in total synthesis of apigenin 7-O- $\beta$-D-cellobioside (1a) and apigenin 7-O- $\beta$-D-cellobiosyl-4'-O- $\beta$-D-glucopyranoside (1c) via four and six steps in a total yield of 56 and $76 \%$ from naringenin (2), respectively. We also synthesized apigenin 7-O- $\beta$-Dglucopyranoside (1b) and apigenin 7,4'-di- $O$ - $\beta$-D-glucopyranoside (1d) from naringenin (2). We also examined two monoglycoside and two diglycoside with polyphenol oxidase (PPO) from potato (Solanum tuberosum). The result showed that 1a inhibited the polyphenol oxidase enzyme activity. The value of $\mathrm{IC}_{50}$ was $1.08 \mathrm{mM}$. 1b was activator effect on polyphenol oxidase enzyme activity. On the other hand, apigenin 7,4'-di-O-glycosides (1c-d) showed no activator and inhibitor effect on polyphenol oxidase enzyme activity.

Keywords: Apigenin 7-O- $\beta$-D-cellobioside, Apigenin 7-O- $\beta$-D-glucopyranoside, Inhibition, Polyphenol oxidase.

\section{INTRODUCTION}

Flavonoid glycosides, as well as their aglycones, are widely distributed in the plant kingdom ${ }^{1}$ and have significant biological activities such as antitumor, antimicrobial and radical-scavenging properties ${ }^{2}$. Sugar moiety usually are found at the $7^{\text {th }}$ position of flavonoid $O$-glycosides but rarely found at the $4^{\text {th }}$ position. Despite their importance, synthesis of flavonoid glycosides was extremely limited ${ }^{3-11}$. There are two critical way on the synthesis of glycosyl flavonoid. The first way is synthesis of the flavonoid skeleton via cyclization after glycosylation.

The second way is direct glycosylation of the flavonoid skeleton that nucleophilicity of the phenolic hydroxyl group at 7-OH is much higher than 4'-OH in flavonoids ${ }^{11-13}$. Actually, direct glycosylation of flavanone skeleton with excess sugar halide and silver carbonate gave only $7-O$-glycosides ${ }^{10}$. In common with many fruits and vegetables, quince fruit contains polyphenol oxidase (monophenol, dihydroxypheny- lalanine: oxygen oxidoreductase, EC 1.14.18.1; polyphenol oxidase) which a bifunctional, copper-containing enzyme widely distributed in the phylogenetic scale using molecular oxygen, catalyses both the $o$-hydroxylation of monophenols to give $o$-diphenols (cresolase activity) and the further oxidation of $o$-diphenols to $o$-quinones (catecholase activity) ${ }^{14-18}$.
The $o$-quinones thus generated are unstable and rapidly react with themselves and with amino acids or proteins, polymerizing to the brown or black pigments ${ }^{17,18}$ that are responsible for melanization in animals and browning in plants. Surface discolouration, commonly called browning or phenolic browning, is a serious problem in marketing and storage. Tissue browning in fruits and vegetables damaged by mechanical injury during harvesting, postharvest storage, or processing is one of the main causes of quality loss and a great problem for the food industry. This reaction, which is mainly catalyzed by polyphenol oxidase (PPO), gives rise to the formation of $o$-quinones, which subsequently polymerize, leading to the appearance of brown pigments ${ }^{18-20}$.

The quinones then condense to form dark pigments. Because the browning is considered unfavourable ${ }^{18-21}$, there has been much interest in polyphenol oxidase among biochemists and food technologists ${ }^{18-23}$. polyphenol oxidase obtained from different plant tissues shows different substrate specificities and degrees of inhibition ${ }^{23}$. Therefore, characterization of the enzyme could help to develop more effective methods for controlling browning of plants and products ${ }^{24,25}$.

Thus, we focused our attention on the total synthesis of two apigenin-7- $O$-glycosides and two apigenin-7,4'-di- $O$-glycosides via direct glycosylation of naringenin (Scheme-I) and examined effect of original apigenin glycosides on polyphenol oxidase. 


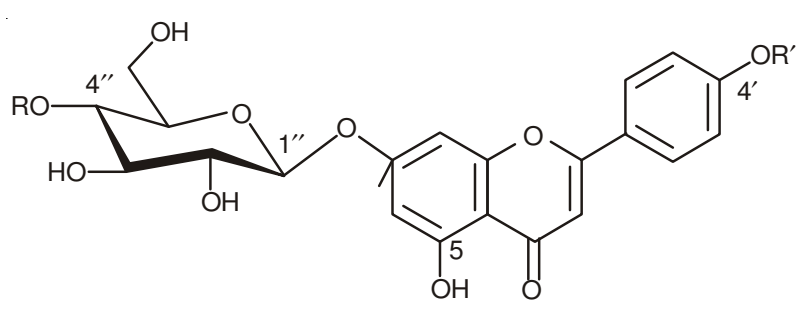

\begin{tabular}{lll} 
& $\mathrm{R}$ & $\mathrm{R}^{\prime}$ \\
\hline 1a & $\beta$-D-Glc & $\mathrm{H}$ \\
1b & $\mathrm{H}$ & $\mathrm{H}$ \\
1c & $\beta$-D-Glc & $\beta-$ - - Glc \\
1d & $\mathrm{H}$ & $\beta-$ D-Glc
\end{tabular}

Scheme-I: Structure of Apigenin-7- $O$-monoglycosides and apigenin-7,4'-Odiglycosides ${ }^{26}$

\section{EXPERIMENTAL}

Melting points were taken on a Yanagimoto micro-melting point apparatus and are uncorrected. IR spectra were measured on a SHIMADZU Prestige-21 (200 VCE) spectrometer. ${ }^{1} \mathrm{H}$ and ${ }^{13} \mathrm{C}$ NMR spectra were measured on spectrometer at VARIAN Mercury Plus at 300 and $75 \mathrm{MHz}$, respectively. ${ }^{1} \mathrm{H}$ and ${ }^{13} \mathrm{C}$ chemical shifts are referenced to the internal deuterated solvent. Mass spectra were obtained using MICROMASS Quattro LC-MS-MS spectrometer. Enzyme assays were carried out with the aid of a Heios a (Unicam) UV-visible spectrophotometer. Flash column chromatography was performed using Merck silica gel 60 (230-400 mesh ASTM). All chemicals were purchased from Merck, Alfa Easer, Sigma-Aldrich and Fluka.

7-O- $\beta$-D-cellobiosyl-apigenin (1a), 7-O- $\beta$-D-glycosylapigenin (1b), 7-O- $\beta$-D-cellobiosyl-4'- $O-\beta$-D-glycosyl-apigenin (1c) and 7,4'-Di- $O$ - $\beta$-D-glycosyl-apigenin $(\mathbf{1 d})$ were synthesized as described in the publication ${ }^{26}$.

Extraction and purification procedure: Potatoe (Solanum tuberosum) (50 g) sample was homogenized using a waring blender for $2 \mathrm{~min}$ in $100 \mathrm{~mL}$ of $0.1 \mathrm{M}$ phosphate buffer $(\mathrm{pH}$ 6.5) containing $10 \mathrm{mM}$ ascorbic acid and $5 \%$ poly(ethylene glycol). The $0.1 \mathrm{M}$ concentration was chosen to avoid the influence of enzymatic extract ionic strength on polyphenol oxidase activity. The homogenate was filtered and the filtrate was centrifuged at $15000 \mathrm{~g}$ for $0.5 \mathrm{~h}$ at $4{ }^{\circ} \mathrm{C}$. The supernatant obtained was used as crude extract. The supernatant was brought to $80 \%\left(\mathrm{NH}_{4}\right)_{2} \mathrm{SO}_{4}$ saturation with solid $\left(\mathrm{NH}_{4}\right)_{2} \mathrm{SO}_{4}$. The preciptated polyphenol oxidase was separated by centrifugation at $15000 \mathrm{~g}$ for $1 \mathrm{~h}$. The precipitate was dissolved in a small amount of homogenization buffer and dialyzed at $4{ }^{\circ} \mathrm{C}$ in the same buffer for $24 \mathrm{~h}$ with three changes of buffer during dialysis. The dialyzed sample was used as the polyphenol oxidase enzyme source in the following experiments. After dialysis, the active fraction was purified with affinity chromotography. The affinity gel used was synthesized according to the method of Arslan et $a l .{ }^{27}$. We determined enzyme activity and $280 \mathrm{~nm}$ protein determination for all tube (Fig. 1).

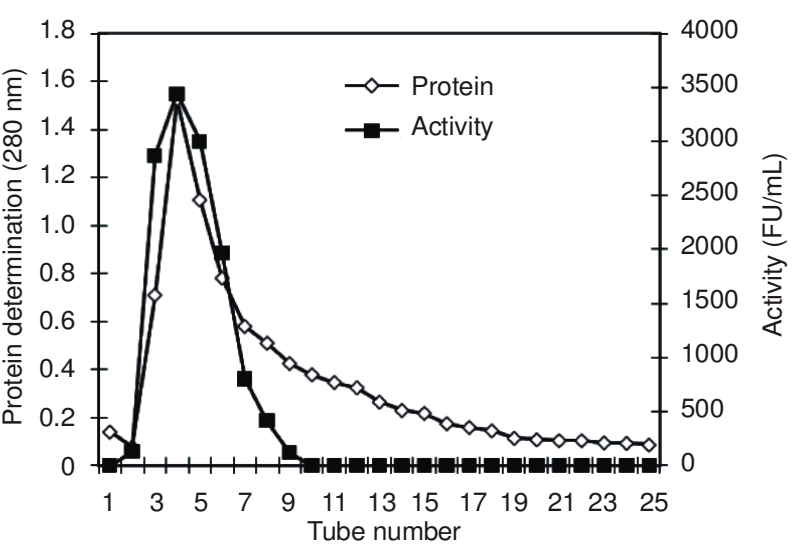

Fig. 1. Purification graphic of polyphenol oxidase

Electrophoresis: Sodium dodecyl sulfate-polyacrylamide gel electrophoresis (SDS-PAGE) was carried out using the method of Laemmli ${ }^{28}$. Samples were applied to $10 \%$ polyacrylamide gels. The slab gels of $1.5 \mathrm{~mm}$ thickness were run at a constant current of $180 \mathrm{mV}$. Gels were stained for protein using a standard Coomassie blue method.

Molecular mass determination: The molecular mass of the purified enzyme was determined by SDS-PAGE (Fig. 4). Affinity chromatography was done according to the method of Arslan and Erzengin ${ }^{27}$. SDS-PAGE was carried out using an SDS protein marker as standard.

Determination of protein content: The protein content was determined according to the Bradford ${ }^{29}$ method using bovine serum albumin as standard.

Spectrophotometric assays: Kinetic assays were carried out by measuring the increase in absorbance at $420 \mathrm{~nm}$ for catechol with a Heios a (Unicam) UV-visible spectrophotometer. Temperature was kept at $25^{\circ} \mathrm{C}$. The reaction was carried out in a $1 \mathrm{~cm}$ light path quartz cuvette. The sample cuvette contained $0,960 \mathrm{~mL}$ of substrates in various concentrations prepared in the homogenization buffer and $0.040 \mathrm{~mL}$ of the enzyme. For each measurement, the volume of solution in the quartz cuvette was kept constant at $1 \mathrm{~mL}$. The reference cuvette contained all of the components except the substrate, with a final volume of $1 \mathrm{~mL}^{27}$.

in vitro Inhibition kinetic studies: For the inhibition studies of original apigenin glycosides different concentration of original compounds were added to the enzyme activity. Polyphenol oxidase enzyme activity with medical drugs was assayed by following the oxidation of catechol. Activity $\%$ values of polyphenol oxidase for six different concentrations of each compound were determined by regression analysis using the Microsoft Office 2000 Excel. Polyphenol oxidase activity without compound was accepted as $100 \%$ activity (Figs. 2 and 3). The inhibitor concentration causing up to $50 \%$ inhibition ( $\mathrm{IC}_{50}$ values) on enzyme were determined from the graphs.

\section{RESULTS AND DISCUSSION}

In this study, we examined effect of synthesized apigenin glycosides derivatives on polyphenol oxidase enzyme activity. The polyphenol oxidase (PPO) of potatoes was first purified by a combination of $\left(\mathrm{NH}_{4}\right)_{2} \mathrm{SO}_{4}$ precipitation, dialysis and a Sepharose 4B-L-tyrosine- $p$-aminobenzoic acid affinity column. 


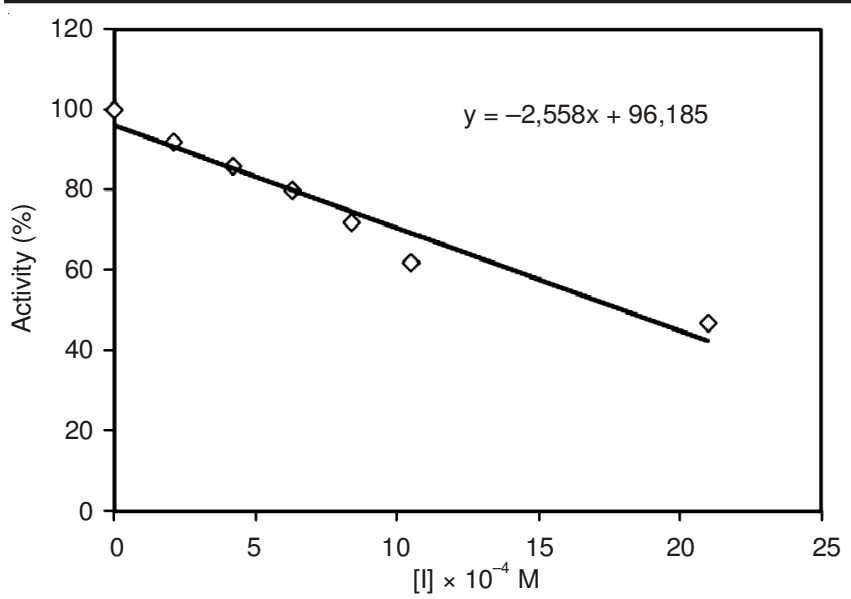

Fig. 2. Value of $\mathrm{IC}_{50}$ in terms of concentration of the apigenin 7-O- $\beta$-Dcellobioside (1a) causing a $50 \%$ reduction of polyphenol oxidase enzyme activity graph

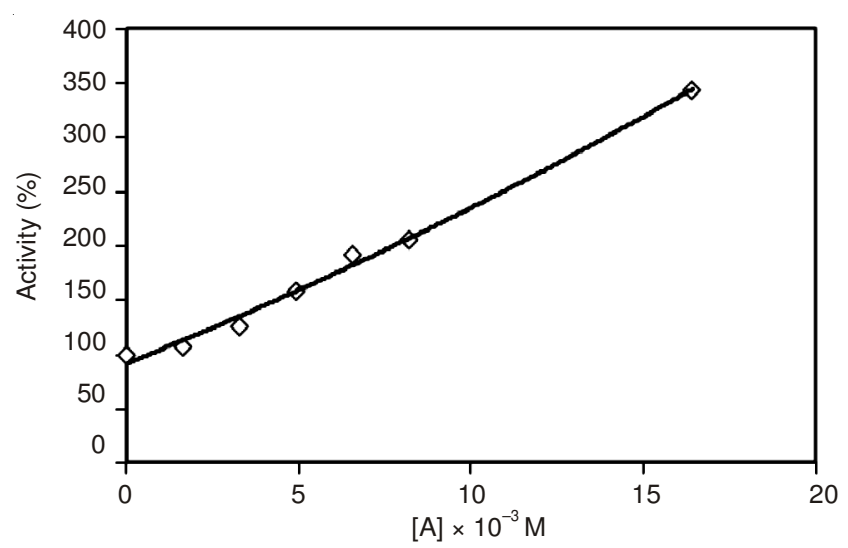

Fig. 3. Effect of apigenin 7-O- $\beta$-D-glucopyranoside (1b) on polyphenol oxidase enzyme activity graph

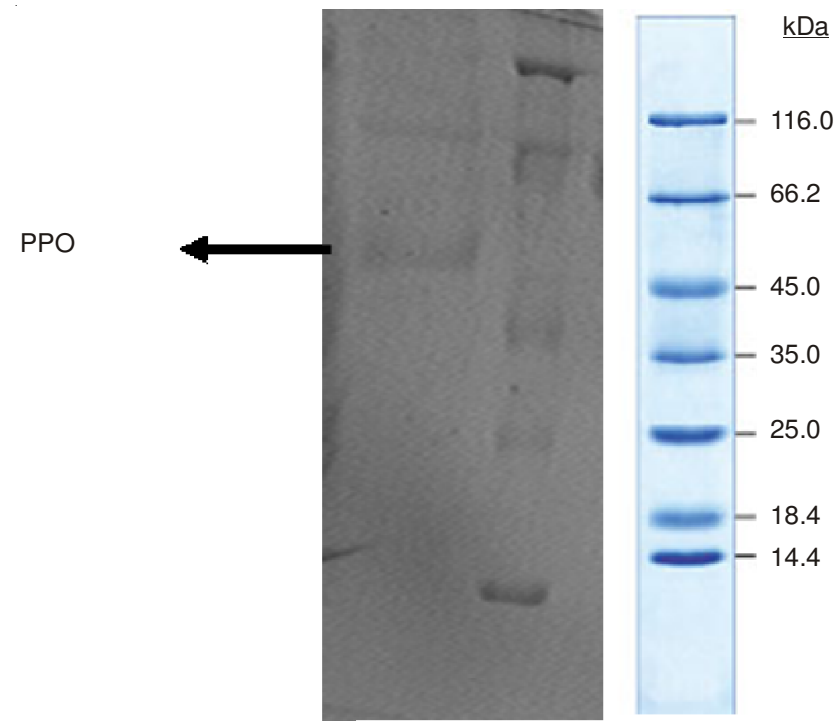

Fig. 4. SDS-PAGE of Polyphenol oxidase. The poled fractions from affinity chromatography was analyzed by SDS-PAGE (12 and $3 \%$ ) and revealed by Coomassie Blue staining. Experimental conditions were as described in the method. Lane 1 contained $5 \mu \mathrm{L}$ of various molecular mass standards: 3-galactosidase, (116.0), bovine serum albumin (66.2), ovalbumin (45.0), lactate dehydrogenase, (35.0), Restriction endonuclease (25.0), 3-lactoglobulin (18.4), lysozyme (14.4)

The purified enzyme migrated as a single band on sodium dodecyl sulfate-polyacrylamide gel electrophoresis.
It is important to examine inhibition effect via compounds on polyphenol oxidase enzyme activity. The prevention or inhibition of enzymatic browning is a major concern of the food industry all over the world and attempts have been made to eliminate from the reaction one or more of its essential components; oxygen, enzyme, copper, or (poly) phenols ${ }^{17}$. In addition, enzymatic browning of fruits and raw vegetables is related to oxidation of phenolic endogenous compounds into highly unstable quinones, which are later polymerized to brown, red and black pigments. Enzymatic browning is also an economic problem for processors and consumers ${ }^{20}$ at least five causes of browning in processed and/or stored fruits and plants are known: enzymatic browning of the phenols, Maillard reaction, ascorbic acid oxidation, caramelization and formation of browned polymers by oxidized lipids. The oxidation of the $o$-diphenols to $o$-quinones by polyphenol oxidase is the most important cause of the change in colour as the $o$-quinones quickly polymerize and produce brown pigments ${ }^{18,20}$. Enzymatic browning of fruits may be delayed or eliminated by removing the reactants such as oxygen and phenolic compounds or by using polyphenol oxidase inhibitors ${ }^{20}$. Complete elimination of oxygen from fruits during the drying process is difficult because oxygen is ubiquitous. Different inhibitors such as sodium metabisulphite, ascorbic acid, D,L-dithiothreitol, sodium cyanide, glutathione, tropolone, thiourea, sodium diethyldithiocarbamate have been used by researchers to prevent the enzymatic browning ${ }^{15,20}$. The inhibitory effects of sodium azide, ascorbic acid, L-cysteine and glutathione on the enzyme activity had tested and $\mathrm{IC}_{50}$ values were estimated to be 23, 51, 62 and $240 \mathrm{mM}$, for parsley (Petroselinum crispum, Apiaceae $)^{30}$. Another study, the diphenolase activities from the two mulberry cultivars were very sensitive to ascorbic acid land metabisulfite with $\mathrm{IC}_{50}$ values lower than $1 \mathrm{mM}^{31}$.

Oxygen can be excluded from the reaction by immersing the fruits and vegetables in water, syrup and brine or by exposure to vacuum or modified atmospheric packing ${ }^{15}$. However, this treatment is not definitive, because when the package is opened, oxygen is reintroduced and browning will restart. The enzyme can be effectively heat-denatured by steam blanching before freezing or carrying food ${ }^{20}$ at the expense of adverse off flavors and texture changes in fresh material ${ }^{20}$. Chemical additives can be used to prevent enzymatic browning: bisulfite, ascorbic acid and its analogs and cysteine as a reducing agent. The most common method for controlling browning is to use sulfites in any of their forms (sulfur dioxide, sodium or potassium metabisulfite, sodium or potassium bisulfite) ${ }^{15,17,20}$. The chemical action of the bisulfites is to react with the $o$-quinones forming colourless complex compounds ${ }^{20}$. Other chemical compounds, such as acidifiers (citric, malic and phosphoric acids), chelators (EDTA) and reducing agents (ascorbic acid, alone or in combination) have been used ${ }^{15}$. However, recent changes in lifestyle and an awareness of the relationship between food and health have led to a demand for safer and fewer added chemicals without toxic effects in processed food ${ }^{6}$.

We investigated apigenin 7- $O$ - $\beta$-D-cellobioside (1a) and apigenin 7-O- $\beta$-D-glucopyranoside (1b) effects in our studies different levels affected the polyphenol oxidase enzyme activity. For the novel derivative shown inhibition effect, the $\mathrm{IC}_{50}$ value of the chemical caused inhibition was determined 
by means of activity percentage-[I] diagram (Fig. 2). Either of them indicated activator effect on the enzyme activity. The result showed that 7-O- $\beta$-D-cellobiosyl-apigenin inhibited the polyphenol oxidase enzyme activity. The value of $\mathrm{IC}_{50}$ was $1.08 \mathrm{mM}$. The value showed us that $1 \mathrm{a}$ was effective inhibitor for polyphenol oxidase (Fig. 2). This compound is candidate to polyphenol oxidase enzyme inhibitor for use in the food industry. On the other hand, $\mathbf{1 b}$ was activator effect on polyphenol oxidase enzyme activity (Fig. 3). 1a is showing inhibitory effects on polyphenol oxidase give rise their effect by bound to active center of enzymes or bound to the other part of enzymes. Conversely, it can be said that the reason of $\mathrm{IC}_{50}$ values changing in respect to enzyme depend to the range, number and kind of enzyme amino acids. Apigenin 7,4'-di- $O$ glycosides (1c-d) showed no activator and inhibitor effect on polyphenol oxidase enzyme activity.

\section{Conclusion}

In summary, the total synthesis of apigenin 7-O- $\beta$-Dcellobioside (1a), apigenin 7-O- $\beta$-D-cellobiosyl-4'-O- $\beta$-Dglucopyranoside (1c), apigenin 7- $O-\beta$-D-glucopyranoside (1b) and apigenin 7,4'-di- $O$ - $\beta$-D-glucopyranoside (1d) from naringenin (2) were successfully carried out.

It is important to examine inhibition effect via compounds on polyphenol oxidase enzyme activity. Especially in this study, 1a was effective inhibitor for polyphenol oxidase. 1a showed similar $\mathrm{IC}_{50}$ value as in previous studies. So here in this study the results were given the apigenin glycoside which is defined $\mathbf{1}$ a could be candidates as inhibitor in order to polyphenol oxidase.

\section{ACKNOWLEDGEMENTS}

The authors greatfully acknowledged to The Scientific and Technological Research Council of Turkey for the financial support of this research granted 105T251. Related to enzyme studies were carried out at Balikesir University Research Center of Applied Sciences (BURCAS).

\section{REFERENCES}

1. V. Vukics and A. Guttman, Mass. Spectrom. Rev., 29, 1 (2010).

2. B.O. Fraser-Reid and K. Tatsuta, in ed.: J. Thiem, Glycoscience: Chemistry and Biology, Springer, Berlin, edn. 3, pp. 14-23 (2001).
3. C.A. Rice-Evans, in ed.: L. Packer, Flavonoids in Health and Disease, Marcel Dekker, New York, pp. 277-295 (1997).

4. S. Murakami, A. Robertson and R. Robinson, J. Chem. Soc., 2665 (1931).

5. H.G. Krishnamurty, V. Krishnamoorthy and T.R. Seshadri, Phytochemistry, 2, 47 (1963).

6. G.A. Iacobucci and J.G. Sweeny, Tetrahedron, 39, 3005 (1983).

7. M. Elhabiri, P. Figueiredo, A. Fougerousse and R. Brouillard, Tetrahedron Lett., 36, 4611 (1995).

8. T. Kondo, K. Oyama, S. Nakamura, D. Yamakawa, K. Tokuno and K. Yoshida, Org. Lett., 8, 3609 (2006).

9. S.T. Caldwell, A. Crozier and R.C. Hartley, Tetrahedron, 56, 4101 (2000).

10. Yang, J. Sun, Z. Yang, W. Han, W.-D. Zhang and B. Yu, Tetrahedron Lett., 53, 2773 (2012).

11. Y. Du, G. Wei and R.J. Linhardt, J. Org. Chem., 69, 2206 (2004).

12. D.J. Maloney and S.M. Hecht, Org. Lett., 7, 1097 (2005).

13. S.T. Caldwell, H.M. Petersson, L.J. Farrugia, W. Mullen, A. Crozier and R.C. Hartley, Tetrahedron, 62, 7257 (2006).

14. F. Garcia-Carmona, E. Valero and J. Cabanes, Phytochemistry, 27, 1961 (1988).

15. S. Dogan, P. Turan, M. Dogan, M. Alkan and O. Arslan, Int. J. Food Sci. Technol., 43, 1316 (2008).

16. M. Perez-Gilabert and F. Garcia-Carmona, J. Agric. Food Chem., 48, 695 (2000).

17. O. Arslan, A. Temur and I. Tozlu, J. Agric. Food Chem., 45, 2861 (1997).

18. A.M.C.N. Rocha and M.M.B. Morais, Int. J. Food Sci. Technol., 36, 425 (2001).

19. A.A. Mayer and E. Harel, in ed.: P.F. Fox, Phenoloxidases and Their Significance in Fruits and Vegetables, In: Food Enzymology, Elsevier Publisher, pp. 373-397 (1991).

20. O. Arslan and S. Dogan, J. Sci. Food Agric., 85, 1499 (2005).

21. T. Richardson and D.B. Hyslop, in ed.: O.R. Fennema, Enzymes: In Food Chemistry, Marcel Dekker, New York, pp. 371-476 (1985).

22. L. Marques, A. Fleuriet and J. Macheix, Plant Physiol. Biochem., 33, 193 (1995).

23. B. Paul and L.R. Gowda, J. Agric. Food Chem., 48, 3839 (2000).

24. R. Yoruk and M.R. Marshall, J. Food Biochem., 27, 361 (2003).

25. J. Yue-Ming, G. Zauberman and Y. Fuchs, Postharvest Biol. Technol., 10, 221 (1997).

26. F. Sonmez, M. Nebioglu, S. Besoluk, M. Arslan, M. Zengin and M. Kucukislamoglu, Nat. Prod. Res., 27, 631 (2013).

27. O. Arslan, M. Erzengin, S. Sinan and O. Ozensoy, Food Chem., 88, 479 (2004).

28. U.K. Laemmli, Nature, 227, 680 (1970).

29. M.M. Bradford, Anal. Biochem., 72, 248 (1976).

30. Y.Z. Dogru and M. Erat, Food Res. Int., 49, 411 (2012).

31. A. Colak, Y. Kolcuoglu, O. Faiz, A. Ozen and B. Dincer, Asian J. Chem. 19, 2961 (2007). 